\title{
Attachment and child behaviour and emotional problems in Autism Spectrum Disorder with intellectual disability
}

Samantha J. Teague ${ }^{1}$

Louise K. Newman ${ }^{1,2}$

Bruce J. Tonge ${ }^{1,3}$

Kylie M. Gray ${ }^{1}$

The MHYPEDD Team*

1. Centre for Developmental Psychiatry and Psychology, Department of Psychiatry, School of Clinical Sciences at Monash Health, Faculty of Medicine, Nursing and Health Sciences, Monash University, Australia

2. Centre for Women's Health, Department of Psychiatry, University of Melbourne, Australia

3. Centre for Educational Development, Appraisal and Research, University of

Warwick, United Kingdom

Corresponding Author:

Dr Kylie Gray

kylie.gray@monash.edu

\section{Acknowledgements and Declarations}

Funding: This study was part of a larger study funded by the Australian National Health and Medical Research Council (grant number 1016919). ST is supported by an Australian Government Research Training Program (RTP) Scholarship.

Compliance with Ethical Standards: All procedures performed in studies involving human participants were in accordance with the ethical standards of the institutional and/or national research committee and with the 1964 Helsinki declaration and its later amendments or

This is the author manuscript accepted for publication and has undergone full peer review but has not been through the copyediting, typesetting, pagination and proofreading process, which may lead to differences between this version and the Version of Record. Please cite this article as doi: 10.1111/JAR.12689

This article is protected by copyright. All rights reserved 
comparable ethical standards. This research was independently reviewed and approved by an ethical board, and was conducted with the understanding and written consent of all individual participants included in the study, in accordance with the above mentioned principles.

Contributions of Authors: ST conceived of the study, participated in its design and coordination, performed the data analysis, interpreted the data, and drafted the manuscript; LN conceived of the study, contributed to the analysis and interpretation of data, and helped to draft the manuscript; BT conceived of the study, participated in its design and coordination, interpretation of the data, and helped to draft the manuscript; KG conceived of the study, participated in its design and coordination, contributed to the interpretation of the data, and helped to draft and revise the manuscript. All authors read and approved the final manuscript

Mental Health of Young People with Developmental Disabilities (MHYPEDD)*: This paper represents a collaborative effort on behalf of the MHYPEDD team. The contribution from authors to this paper was part of a broader collaborative effort from MHYPEDD team members. We request that investigators who are members of MHYPEDD be listed at the end of the manuscript.

MHYPEDD Team: Aery, A., Andersson, E., Arciuli, J., Arora , S., Bezzina, L., Blackmore, R., Borland, R., Caruana, J., Cawood, D., Clarke, K., Day, J., Dossetor, D., Einfeld, S., Emerson, E., Evans, H., Fernandez, A., Goodall, S., Gray, K. M., Haas, K., Henderson, K., Henry, T., Hinton, S., Hoath, F., Hodges, J., Horstead, S., Howlin, P., Hu, N., Keating, C., Kelly, E., Knott, R., Kotselas, P., Louie, E., McAuliffe, Z., O’Hagan, G., Panahi, B., Phillis, K., Rice, L., Rose, O., Rotolone, C., Salvador-Carulla, L., Sanders, M., Schoch, M., Shortt, F., Silove, N., Sofronoff, K., Stace, L., Taffe, J., Teague, S. J., Thompson, D. M., Tonge, B. J., Viney, R., \& Wallman, E.

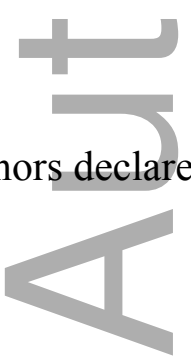

\section{Conflict of Interest}

The authors declare that they have no conflict of interest. 
DR. KYLIE M GRAY (Orcid ID : 0000-0001-6518-4240)

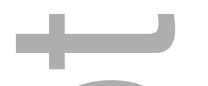

Article type : Original Article

Attachment and child behaviour and emotional problems in Autism Spectrum Disorder with intellectual disability

[Author details withheld]

\section{Abstract}

\section{Background}

Behaviour and emotional problems are highly prevalent in children with Autism Spectrum Disorder (ASD). In typically developing children, attachment quality acts as a risk/protective factor for behavioural outcomes and adjustment, warranting investigation in children with ASD.

\section{Method}

We investigated the relationship between attachment and child behaviour and emotional problems in children with ASD and comorbid intellectual disability. Data were collected from parent-child dyads where children were diagnosed with ASD and ID ( $n=28)$ or other developmental disabilities $(\mathrm{n}=20)$.

\section{Results}

Children with ASD had higher levels of behaviour and emotional problems and more attachment difficulties than children with other developmental disabilities. Poorer attachment quality contributed uniquely to the variance in child behaviour and emotional problems.

\section{Conclusions}

Interventions targeting behaviour and emotional problems in children with ASD may benefit from an attachment model which addresses the child's difficulty in using caregivers as a coregulatory agents of emotions. 
Attachment and behaviour and emotional problems in ASD

\section{Keywords}

attachment; behaviour and emotional problems; autism; intellectual disability; developmental delay

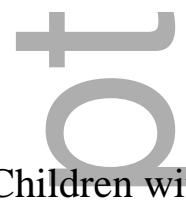

\section{Introduction}

Children with Autism Spectrum Disorder (ASD) have higher rates of behaviour and emotional problems than typically developing children and children with other developmental disabilities (Brereton, Tonge, \& Einfeld, 2006; Einfeld et al., 2006; McCarthy et al., 2010). Behaviour and emotional problems are common in children with developmental disabilities. Approximately $40 \%$ of children with intellectual disabilities have clinically significant comorbid behaviour and emotional problems - a prevalence rate 3-4 times higher than in typically developing children (Emerson, 2003; Tonge \& Einfeld, 2000). In children with ASD, the rate of behaviour and emotional problems is even higher, adversely affecting up to $73.5 \%$ (Brereton et al., 2006). Children with ASD are particularly challenged by elevated hyperactivity, disruptive behaviours (e.g. tantrums, and impatient and stubborn behaviour), self-absorbed behaviours, and anxious behaviours (Brereton et al., 2006; Totsika, Hastings, Emerson, Lancaster, \& Berridge, 2011). These problems are long-lasting, and are identified as a key risk factor for poorer adult outcomes (Gray et al., 2016; Herring et al., 2006).

A number of potential risk and protective factors may be involved in the developmental trajectory of behaviour and emotional problems in children with ASD. Compared with the literature on typically developing children, relatively little is known about the predictors of positive outcomes for children with ASD (Szatmari et al., 2016; Vaillancourt et al., 2017). Factors associated with the presence and maintenance of behaviour and emotional problems in ASD samples include: greater severity of autism symptoms, comorbid intellectual disability, and male gender (Brereton et al., 2006; Emerson, Einfeld, \& Stancliffe, 2010; Gray, Keating, et al., 2012; Herring et al., 2006; Janssen, Schuengel, \& Stolk, 2002; McCarthy et al., 2010). Familial factors are also associated with behaviour and emotional problems in children with ASD, including poor parent mental health, parenting stress, adverse parenting practices, poor family functioning, and socioeconomic disadvantage (Emerson \& Hatton, 2007; Herring et al., 2006; Totsika, Hastings, Vagenas, \& Emerson, 2014; Woodman, Smith, Greenberg, \& Mailick, 2015). An area that has received significantly less attention as a correlate of behaviour and emotional problems in children 
with ASD is the quality of the child-parent relationship, specifically attachment (Teague, Gray, Tonge, \& Newman, 2017).

Attachment is the neurobiological system underlying the innate relational bond between children and caregivers that is formed to ensure the child's safety and survival (Ainsworth, 1985; Bowlby, 1977). In typically developing children, the quality of parentchild interactions determines attachment quality; sensitive and responsive caregiving results in a secure attachment, while poor caregiving quality may result in an insecure (avoidant, resistant, or disorganised) or clinically disturbed attachment (Ainsworth, Bell, \& Stayton, 1971, 1974). Secure attachment acts as a protective developmental factor, while insecure/disorganised attachment is associated with behaviour and emotional problems in childhood and other psychopathology into adulthood (Fearon, Bakermans-Kranenburg, Van IJzendoorn, Lapsley, \& Roisman, 2010; Greenberg, Speltz, \& Deklyen, 1993; Sroufe, 2005; van Ijzendoorn, Schuengel, \& Bakermans-Kranenburg, 1999; Werner, 1989).

The are several potential explanations for the importance of child attachment quality in the development and maintenance of behaviour and emotional problems (Fearon et al., 2010; Greenberg et al., 1993; Janssen et al., 2002). Firstly, behaviour and emotional problems may be a suboptimal strategy serving an attachment-related goal (Greenberg et al., 1993). Noncompliance, tantrums, excessive clinging, and other behaviour and emotional problems may be used by the child to achieve comfort from or proximity to caregivers, particularly in the context of inaccessible, insensitive, or non-responsive caregiving. Secondly, insecure children may be reliant on secondary coping processes when feeling distressed (Fearon et al., 2010). Attachment figures act as co-regulatory agents of children's emotions, offering support and comfort when children are distressed. However, insecure children may not be able to rely on their attachment figures for support or comfort due to previous discouragement or inconsistency from caregivers, and thus may not develop the selfregulation skills required to deal with stress and challenges (Fearon et al., 2010). This explanatory framework is particularly relevant for children with developmental disabilities, where families function in stressful environments with known precursors to insecure attachment such as poor parent mental health and ineffective parenting practices (Gray et al., 2011; Janssen et al., 2002; Teague et al., 2018). Finally, children may develop internal working models that are characterised by emotional instability (Greenberg et al., 1993). Attachment theory predicts that the quality of parent-child interactions shape the development of children's internal working model - a cognitive schema of their expectations 
and attitude towards themselves and their relationships, which in turn shapes their interpretation of events within the environment (Bowlby, 1969, 1973). Thus, children with insecure attachments may develop an internal working model characterised by mistrust, chaos, and antisocial behaviours, affecting their sense of competence and self-esteem (Fearon et al., 2010; Greenberg et al., 1993).

Historically, attachment disturbances were considered part of the symptomatology of ASD (American Psychiatric Association, 1980). Early conceptualisations of the aetiology of autism implicated cold and distant parenting practices resulting in children who were incapable of forming attachment bonds to caregivers (Bettelheim, 1959; Kanner, 1943). However, substantial research has now demonstrated that children with ASD do form attachment bonds to caregivers (Rutgers, Bakermans-Kranenburg, van Ijzendoorn, \& van Berckelaer-Onnes, 2004; Teague et al., 2017), that the sensitivity of the caregiving they receive is equivalent to that observed in dyads of parents and typically developing children (van Ijzendoorn, Rutgers, Bakermans-kranenburg, et al., 2007), and that biological factors provide a stronger causal pathway in the development of ASD (Folstein \& Rutter, 1977a, 1977b). The long-lasting impact of such conceptualisations has impeded research into relational factors associated with the development of autism, particularly those investigating child-parent interactions (McKenzie \& Dallos, 2017).

Despite being capable of forming discriminate, secure attachments to caregivers, children with ASD with comorbid intellectual disability are reported to have higher rates of attachment insecurity than reported in both typically developing children and children with other developmental disabilities (Rutgers et al., 2004; Teague et al., 2017). The socialcommunication and interaction difficulties characteristic of ASD pose a challenge for the formation of secure bonds to caregivers, and may also pose a challenge for caregivers to tunein to their child's subjective state (Cortina \& Liotti, 2010; Stern, 2004). Forty-seven percent (47\%) of children with ASD demonstrate secure attachments to caregivers, compared with approximately $60 \%$ of typically developing children (Ainsworth, Blehar, Waters, \& Wall, 1978; Teague et al., 2017; Willemsen-Swinkels, Bakermans-Kranenburg, Buitelaar, van IJzendoorn, \& van Engeland, 2000). Importantly, attachment in children with ASD appears to serve the same core functions identified in typically developing children, namely, providing safety and comfort when children explore their environment or feel distressed (Teague et al., 2017). Two key correlates of insecure attachment in children with ASD are the severity of ASD symptomatology and the presence of comorbid intellectual disability, with continuing 
Attachment and behaviour and emotional problems in ASD

debate over which factor is a stronger risk factor (Teague et al., 2017). Children with both ASD and comorbid ID are at greater risk of forming insecure or disorganised attachments than both typically developing children and children with other developmental disabilities (Rutgers et al., 2004; Teague et al., 2017). The association between sensitive caregiving practices and secure child attachment has mixed support in samples of children with ASD (Koren-Karie, Oppenheim, Dolev, \& Yirmiya, 2009; van Ijzendoorn, Rutgers, BakermansKranenburg, et al., 2007), suggesting that the difficulties in social communication characteristic of ASD may pose a challenge for children and parents alike in understanding and predicting each other's behaviour and intent. Further, issues surrounding the similar symptomatology of autism and disorders of attachment present an ongoing challenge for researchers and clinicians alike in determining whether or not the two conditions are related, and how best to differentiate each condition using standardised measures (Davidson et al., 2015; Green, 2003; Mayes, Calhoun, Waschbusch, \& Baweja, 2017; McKenzie \& Dallos, 2017; Teague et al., 2017).

Attachment theory provides a useful framework from which to consider behaviour and emotional problems in children with ASD. Sivaratnam et al. (2015) discuss the need for an attachment-perspective in research on emotion processing in children with ASD, noting that our understanding of the influence of neurobiological factors is further developed than that of environmental factors such as attachment. Janssen et al. (2002) provide a useful attachment-based framework to conceptualise the development and maintenance of behaviour and emotional problems in people with intellectual and developmental disabilities. The combination of increased psychological stress, limited coping skills, and high rates of insecure attachment may contribute to behaviour and emotional problems within intellectual disability groups.

Little is known of the relationship between attachment and child behaviour and emotional problems in ASD. A recent review identified only one article investigating this relationship within parent-child with ASD dyads, examining a sample of children with ASD without intellectual disability and a sample of typically developing children (Bauminger, Solomon, \& Rogers, 2010; Teague et al., 2017). This study found that neither attachment security nor the quality of parent-child relationships contributed significantly to the variance in behaviour and emotional problems in a sample of US and Israeli children with ASD (Bauminger et al., 2010). The lack of available research is surprising given substantial calls from the literature to investigate this relationship (Huebner \& Thomas, 1995; Janssen et al., 
2002; McKenzie \& Dallos, 2017; Silber, 1989; Sivaratnam et al., 2015; Teague et al., 2017; van Ijzendoorn, Goldberg, Kroonenberg, \& Frenkel, 1992). Research is particularly needed in children with comorbid ID, who have high rates of behaviour and emotional problems, are more likely to develop insecure attachments than children with ASD without intellectual disability, and are currently underrepresented in research to date (Russell et al., 2019; Rutgers et al., 2004; Teague et al., 2017).

The overall purpose of this study was to examine the unique effect of ASD symptomatology in the relationship between attachment and child behaviour and emotional problems in children with comorbid ID. The first aim was to compare attachment quality and behavioural and emotional problems between children with ASD (with ID) and children with other developmental disabilities. It was hypothesised that the ASD sample would experience more attachment difficulties and child behaviour and emotional problems than the comparison sample. Secondly, this study aimed to explore the relationship between attachment quality and behaviour and emotional problems, hypothesising that insecure and clinically disturbed attachment would be associated with behaviour and emotional problems. Finally, we aimed to examine whether attachment uniquely contributed to the variance in behaviour and emotional problems in children with ASD. We hypothesised that attachment variables would contribute to child behaviour and emotional problems independent of degree of autism symptoms. In so doing, this work extends Bauminger et al.'s (2010) work by exploring the relationship between attachment and child behaviour and emotional problems in children with ASD with comorbid ID, and examines the unique effect of ASD symptomatology within ID samples.

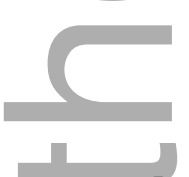

\section{Method}

\section{Recruitment and procedure}

The current study recruited a subsample of caregivers and children with ASD or other Developmental Disabilities (DD) from the Stepping Stones Triple P population-level trial; a trial of a parent-training program for behaviour and emotional problems in children with developmental disabilities (Trial registration: ACTRN12613000803796) (Sofronoff, Gray, Einfeld, \& Tonge, 2018). Families were eligible to participate in this trial if their child was aged 2-12 years and had an intellectual disability (if aged 6+ years) or developmental delay (if aged <6 years) diagnosed by a paediatrician, psychiatrist, psychologist, neurologist, or 
speech pathologist. Children's diagnoses were confirmed through the provision of clinical assessment reports, with families invited to participate if children aged over 6 years scored below 75 on a standardised test of cognitive ability or adaptive behaviour skills (e.g. Vineland II, Sparrow, Cicchetti, \& Balla, 2005) or below 85 for children aged under 6 years.

For the current study, a subsample of families were invited to participate in an additional study focussed on attachment in children with intellectual disabilities/developmental delay. All assessments were completed at baseline, prior to initiation of the intervention. To be included in the ASD group, the diagnosis of ASD was supported through the review of clinical assessment reports. Further, children's degree of ASD symptomatology was assessed using the Social Responsiveness Scale-2 (SRS-2; Constantino \& Gruber, 2012). Children in the other developmental disabilities group who also met the SRS-2 cut-off score for ASD but had not been diagnosed with ASD (and potentially had not been assessed) were excluded from the study. After meeting the larger study eligibility criteria, families were invited to complete a questionnaire assessing family demographics, child behaviour and emotional problems, and parenting practices. Families involved in the current study were then invited to complete an additional assessment of attachment quality and ASD symptomatology, detailed below. As families in the subsample were located across the state of Victoria, Australia, flexibility in data collection methods were offered to participants, including online or postal questionnaire completion, and face-to-face or phone interviews. This study was approved by the XXXXX (Withheld for blind peer review) Human Research Ethics Committee (XXXXX Approval No. 2013000143). Written informed consent was obtained from all participants.

\section{Measures}

Child attachment. Primary caregivers completed the Child-Parent Relationship Scale (CPRS) to provide a proxy assessment of children's attachment behaviours in the home. The CPRS is a widely-used 15-item parent-report questionnaire assessing children's attachment relationship with caregivers (Driscoll \& Pianta, 2011). Items were developed from the Attachment Q-Set; a home-observation direct assessment of children's attachment behaviours (Waters \& Deane, 1985). Parents' rate statements on a five-point Likert-scale from definitely does not apply to my relationship with my child to definitely applies to my relationship with my child. The CPRS has two subscales, closeness (e.g. "If upset, my child will seek comfort from me") and conflict (e.g. "My child and I always seem to be struggling with each other") within the relationship. A continuous measure of attachment security can also be calculated 
by summing the item scores and reverse-coding the conflict subscale items, resulting in a total positive relationship score (Pianta, 2015).

The CPRS is shown to have strong internal consistency, with Driscoll and Pianta (2011) reporting Cronbach's alphas of 0.64 and 0.84 for the closeness and conflict subscales, respectively. Within ASD and ID populations, Cronbach's alphas of 0.91 and 0.81 are demonstrated for the closeness and conflict subscales, respectively (Totsika et al., 2014). Driscoll and Pianta (2011) also initially explored the concurrent validity of the CPRS by assessing against coded videotapes of structured interactions between parents and their typically-developing children, finding that the highest correlations were observed between the CPRS closeness subscale and observer's ratings of a supportive presence, sensitivity, and positive caregiving, and the CPRS conflict subscale of and observer's ratings of hostility. The CPRS has also been assessed alongside the Strange Situation Paradigm (Holland \& McElwain, 2013) and the Attachment Q-Sort (O’Connor, Scott, McCormick, \& Weinberg, 2014), demonstrating that secure attachment is associated with less conflict and more closeness in child-mother attachment relationships.

To assess clinically disturbed attachment behaviours, caregivers were also interviewed using the Disturbances of Attachment Interview (DAI). The DAI is a 12-item semi-structured interview assessing signs of clinical disturbances of children's attachment, including inhibited (e.g. child does not seek comfort preferentially from caregiver) and disinhibited behaviours (e.g. child does not exhibit reticence with unfamiliar adults) (Zeanah, Smyke, Koga, \& Carlson, 2005). The DAI also assesses disturbances within attachment relationships known as secure-base distortions, including self-endangering, excessive clinging, fearful/hypervigilant, and role-reversal attachment behaviours. Parents are asked whether their child demonstrates specific attachment behaviours, and asked to provide a recent example of their child's typical behaviour. Items are then coded on a 0,1 , or 2 scale to determine whether a pattern of behaviour is present. Studies have demonstrated that the DAI has strong internal consistency (Cronbach's alphas of 0.83 and 0.80 for the inhibited and disinhibited subscales, respectively), as well as strong interrater reliability $(\kappa=0.88)$ (Smyke, Dumitrescu, \& Zeanah, 2002). Within ASD and ID populations, the DAI has also demonstrated strong internal consistency (Cronbach's alphas of 0.90 for the combined DAI inhibited and disinhibited items) and interrater reliability (intraclass correlations of 0.88 and 0.98 for the inhibited and disinhibited scales, respectively) (Giltaij, Sterkenburg, \& Schuengel, 2015). The DAI also has strong concurrent validity, demonstrating $85.8 \%$ 
concordance between the Preschool Age Psychiatric Assessment (PAPA) and DAI disinhibited attachment scales and $98.3 \%$ concordance for the PAPA and DAI inhibited attachment scales (Gleason et al., 2011).

Behaviour and emotional problems. Parents completed the Developmental Behaviour Checklist (DBC2) to assess children's behaviour and emotional problems. The DBC2-P is a 96-item parent-report measure of children's behaviour and emotional problems, designed specifically for children with intellectual disability or developmental delay (Einfeld \& Tonge, 1995; Gray, Tonge, Einfeld, Gruber, \& Klein, 2018). Caregivers are asked to report whether their child demonstrates a behaviour using a rating scale of 0 to 2, where 0 is Not true as far as I know and 2 is Very true or often true. The DBC2-P was completed with parent-child dyads where children were aged over 4 years, and the DBC-Under 4 (DBC-U4) was completed where children were aged under 4 years (Gray, Sweeney, et al., 2012; Gray et al., 2018). A Total Behaviour Problems Score can be calculated to determine an overall level of behaviour and emotional problems (Taffe, Tonge, Gray, \& Einfeld, 2008). Scores were calculated for each DBC2 subscale, namely Disruptive, Self-Absorbed, Communication Disturbance, Anxiety, and Social Relating. Children rated using the DBC-U4 had their scores transformed to match the item rating system and subscales of the DBC2-P.

The DBC has strong internal consistency (Cronbach's alpha $=.94$ for the DBC-P Total Behaviour Problem score, and ranging from 0.66 to 0.91 across subscales), high interrater reliability (intra-class correlation $=.80$ between parents), as well as high test-retest reliability (intra-class correlation $=0.83)($ Einfeld $\&$ Tonge, 2002). The DBC is also demonstrated to have strong concurrent validity, assessed alongside clinician's agreement (Einfeld \& Tonge, 2002; $\kappa=0.70$ ), the Maladaptive Behaviour Scale (Lambert \& Windmiller, 1981; $r=0.86$ ), the Problem Behaviour section of the Scales of Independent Behaviours (Bruininks, Hill, \& Morreau, 1988; r=0.72), and the Strength and Difficulties Questionnaire (Rice et al., 2018; $r=0.74$ ).

Autism symptoms. Caregivers in both groups also reported children's autism symptom severity using the Social Responsiveness Scale (SRS-2). The SRS-2 is a 65-item parent-report questionnaire of children's social impairment associated with autism (Constantino \& Gruber, 2012; Frazier et al., 2014). Parents rate the extent to which they have observed their child demonstrating a behaviour associated with autism in their home on a Likert scale from 1 to 4, where 1 is Not true and 4 Almost always true. The SRS-2 (School 
Age) was used with parent-child dyads where the child was aged over 4 years, and the SRS-2 (Preschool) was used for children aged under 4 years. SRS-2 items load onto five subscales: Social Awareness, Social Cognition, Social Communication, Social Motivation, and Restricted Interests and Repetitive Behaviour. An overall score for social impairment, the Total Social Impairment Severity Score, can also be calculated. The SRS-2 has demonstrated strong psychometric properties. The predictive validity of the SRS-2 indicates that the measure is effective at distinguishing between children with and without ASD, with values of 0.92 reported for both sensitivity and specificity estimates (Bruni, 2014). Further, high convergent validity is demonstrated with other autism rating scales, such as the Childhood Autism Rating Scale, and moderate correlations with ASD diagnostic instruments such as the Autism Diagnostic Interview-Revised (ADI-R) (Bruni, 2014; Constantino \& Gruber, 2012). The reliability of the SRS-2 is also demonstrated to be strong, with estimates of internal consistency with correlations ranging from 0.94 to 0.96 across age groups and inter-rater reliability correlations ranging of 0.77 and 0.61 for the School-Age and Preschool versions, respectively (Bruni, 2014; Constantino \& Gruber, 2012).

Socio-economic advantage. Family's socio-economic advantage was classified using the Socio-Economic Indexes for Areas (SEIFA) data package (Australian Bureau of Statistics, 2013). SEIFA provides an estimate of a relative socio-economic advantage and disadvantage of residential postcodes, ranked using a decile system. Relative socio-economic advantage and disadvantage is assessed by the populations' ability to access material and social resources, and their ability to participate in society.

\section{Analysis}

Analyses were performed using SPSS Version 23 (SPSS, 2013), using baseline data of the study. First, differences between the overall sample and the CPRS, DAI, and DBC2 norms were calculated using independent samples t-tests. Second, differences between the ASD and other developmental disabilities groups on the CPRS, DAI and DBC2 were examined using independent samples t-tests. Next, Pearson's correlations were then calculated within each group to examine associations between behaviour and emotional problems (DBC2), attachment quality (CPRS and DAI), and ASD symptomatology (SRS-2). Finally, regression analyses were conducted for the DBC2 total and subscale scores to examine whether attachment variables were associated with behaviour and emotional problems after controlling for other theoretically-relevant factors. 
As this study was completed using a relatively small sample size, consideration was given to the appropriateness of statistical methods. Between-group comparisons were performed for each variable using two groups only, negating the need for corrections (Bender \& Lange, 2001). To maximise statistical power, regression analyses were performed using the combined sample with the presence/absence of an ASD diagnosis entered as an independent variable. We conducted power analysis using the correlation between the CPRS and the SDQ from previous studies (Totsika et al., 2014), and the power is 0.86 given the sample size of 45 in this study (type I error $=.05$ ). Other variables were only entered into the regression model if a significant association was demonstrated via the Pearson's correlations analysis conducted previously. Exact p-values are reported for all analyses.

\section{Results}

\section{Participants}

The final sample consisted of 48 parent-child dyads, with 28 children diagnosed with ASD and 20 diagnosed with other developmental disabilities (see Table 1). The diagnoses of children without ASD included Down syndrome $(n=7)$, cerebral palsy $(n=1)$, Williams syndrome $(n=2), 22 q 11$ deletion syndrome $(n=2)$, and cause unknown $(n=8)$. Most parent participants were mothers, with only one parent in each group a father to the participating child. No differences were found between groups for child age, relationship between the primary caregiver and the child, or Vineland Adaptive Behaviour Composite. Two differences were observed between the ASD group and the comparison group of children with other developmental disabilities. The ASD group had significantly greater proportion of males than the other developmental disabilities group $\left(X^{2}(2, \mathrm{~N}=48)=4.29, \mathrm{p}=.04\right)$, with a ratio of approximately 4:1 male-to-female within the ASD sample. As would be expected, the ASD group had higher rates of symptoms of autism compared to the group of children with other developmental disabilities $(\mathrm{t}(46)=6.85, \mathrm{p}=.00)$.

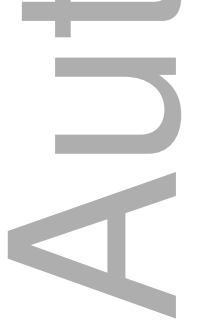

\section{INSERT TABLE 1 ABOUT HERE}

\section{Behaviour and Emotional Problems}

Independent samples t-tests were performed to investigate whether children with ASD had higher rates of behaviour and emotional problems than children with other developmental 
disabilities. Results are summarised in Table 2. Both groups reported significantly higher DBC2 subscale and Total Problem Behaviour scores than reported in Australian community normative samples of children and adolescents with intellectual disability (current sample: $\mathrm{M}(\mathrm{SD})=0.70$ (0.32); Australian normative ID sample: $\mathrm{M}(\mathrm{SD})=0.45(0.04) ; \mathrm{t}(500)=12.5$, $\mathrm{p}=.00$; Einfeld \& Tonge, 1996a, 1996b). Between groups, parents of children with ASD reported that their children experienced a significantly higher DBC2 Total Problem Behaviour score than parents of children with other developmental disabilities, and greater mean item scores on all of the DBC2-P subscales, including Disruptive, Self-Absorbed, Communication Disturbance, Anxiety, and Social Relating.

\section{INSERT TABLE 2 ABOUT HERE}

\section{Attachment Quality}

Independent samples t-tests were performed to investigate whether children with ASD had poorer attachment quality than children with other developmental disabilities. Results are summarised in Table 2. Caregivers in this study reported significantly less closeness and more conflict in their child's attachment behaviours than those of typically developing children in previous studies with normative samples (conflict $\mathrm{t}(1061)=8.64, \mathrm{p}<.01$; closeness $\mathrm{t}(1061)=27.77, \mathrm{p}<.01$; Driscoll \& Pianta, 2011). Between groups, caregivers of children with ASD reported significantly less closeness in their child's attachment behaviours than caregivers of children with other developmental disabilities; however, the degree of conflict in children's attachment behaviours did not differ. Children with ASD had a significantly lower Total Positive Relationship score than children with other developmental disabilities. For disturbed attachment behaviours, caregivers of children in both groups reported significantly more inhibited and disinhibited attachment behaviours than in typically developing samples (inhibited $\mathrm{t}(79)=9.18, \mathrm{p}<.01$; disinhibited $\mathrm{t}(79)=9.95, \mathrm{p}<.01 ;$ Smyke, Dumitrescu, \& Zeanah, 2002). Between groups, caregivers of children with ASD reported significantly more inhibited attachment behaviours than caregivers of children with other developmental disabilities. No differences were found between groups for children's disinhibited attachment behaviours, nor for self-endangering, excessive clinging, fearful, or controlling secure-base distortions. 


\section{Associations between Behaviour and Emotional Problems, Attachment Quality, and ASD Symptomatology}

Pearson's correlations were conducted to investigate associations between child behaviour and emotional problems and children's age, gender, socio-economic advantage, attachment quality, ASD symptomatology, and adaptive behaviour skills (presented in Table 3). As per Cohen's conventions (1988), for the ASD group, higher DBC2 Total Problem Behaviour scores were strongly associated with socioeconomic disadvantage, more severe ASD symptomatology, and less positive attachment relationships. Associations at the subscale level were as follows: the DBC2 Self-Absorbed subscale was moderately associated with more severe ASD symptomatology only; the DBC2 Communication Disturbance subscale was moderately associated with less positive attachment relationships and strongly associated with more severe ASD symptomatology; and finally, the DBC2 Anxiety subscale was strongly associated with less positive attachment relationships and more severe ASD symptomatology; the DBC2 Social Relating subscale was strongly associated with more severe ASD symptomatology and less positive attachment relationships, and moderately associated with more inhibited attachment behaviours.

For children with other developmental disabilities, higher DBC2 Total Problem Behaviour scores were moderately associated with more severe ASD symptomatology and less positive attachment relationships. Associations at the subscale level were as follows: the DBC2 Disruptive subscale was strongly associated with less positive attachment relationships only; the DBC2 Communication Disturbances subscale was associated with younger age only; and finally the DBC2 Social Relating subscale was strongly associated with more severe ASD symptomatology. There were no statistically significant associations between these variables and the DBC2 Self-Absorbed or Anxiety subscales.

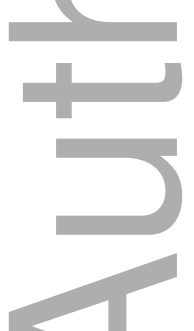

INSERT TABLE 3 ABOUT HERE

Multivariable regressions were performed using the combined sample to investigate whether attachment factors contributed independently to the variance of children's behaviour and emotional problems. A series of regression models were constructed to predict each DBC2 subscale with ASD diagnosis and socioeconomic disadvantage (SEIFA) entered as independent variables into each model, selected for inclusion based on their association with 
each DBC2 subscale in the correlation analyses completed previously. Considering the strong collinearity between child-parent attachment relationship and attachment behaviours, two models were created for each DBC2 subscale, with Model 1 using the quality of child-parent attachment relationships (CPRS Total Positive Relationship), and Model 2 using children's inhibited and disinhibited attachment behaviours (DAI).

Results of each regression model are presented in Table 4. Model 1 significantly predicted children's behaviour and emotional problems across all DBC2 subscales. Specifically, the DBC2 Total Behaviour Problem score was significantly associated with less positive attachment relationships, ASD diagnoses, more socioeconomic disadvantage, which together explained $57 \%$ of the variance $\left(\mathrm{F}_{(3,44)}=24.01, \mathrm{p}<.001\right)$. Both the DBC2 Disruptive and Self-Absorbed subscales were associated with less positive attachment relationships only, explaining $51 \%$ of the variance of the Disruptive subscale $\left(F_{(3,44)}=19.58, p<.001\right)$ and $25 \%$ of the Self-Absorbed subscale $\left(\mathrm{F}_{(3,44)}=6.92, \mathrm{p}<.01\right)$, respectively. The DBC2 Communication Disturbance subseale was associated with less positive attachment relationships and more socioeconomic disadvantage, explaining $30 \%$ of the variance $\left(F_{(3,44)}=8.72, p<.001\right)$. Finally, both the DBC2 Anxiety and Social Relating subscales were associated with less positive attachment relationships, ASD diagnoses, and more socioeconomic disadvantage, explaining $51 \%$ of the Anxiety subscale $\left(\mathrm{F}_{(3,44)}=19.42, \mathrm{p}<.001\right)$ and $54 \%$ of the Social Relating subscale $\left(\mathrm{F}_{(3,44)}=22.12, \mathrm{p}<.001\right)$.

For Model 2, significant models were developed for all DBC2 subscales except for the DBC2 Disruptive scale. The DBC2 Total Behaviour Problem subscale was associated with an ASD diagnosis and more socioeconomic disadvantage, explaining $28 \%$ of the variance $\left(\mathrm{F}_{(3,44)}=6.02, \mathrm{p}<.01\right)$. This finding was replicated across the DBC2 Communication Disturbance $\left(\mathrm{F}_{(3,44)}=3.44, \mathrm{p}=.02\right.$, Adj $\left.\mathrm{R}^{2}=0.16\right)$, Anxiety $\left(\mathrm{F}_{(3,44)}=6.19, \mathrm{p}<.001, \operatorname{Adj}^{2}=0.28\right)$, and Social Relating subscales $\left(\mathrm{F}_{(3,44)}=11.37, \mathrm{p}<.001\right.$, Adj $\left.\mathrm{R}^{2}=0.44\right)$. Attachment disturbances were only associated with the DBC2 Self-Absorbed subscale, specifically disinhibited attachment behaviours and the presence of an ASD diagnosis, explaining $21 \%$ of the variance $\left(\mathrm{F}_{(3,44)}=4.53, \mathrm{p}<.01\right)$.

INSERT TABLE 4 ABOUT HERE 


\section{Discussion}

This study aimed to examine the relationship between attachment and child behaviour emotional problems in an ASD sample with comorbid ID. The primary contribution of this study is to assist in understanding of the influence of family factors on emotional and behavioural disorders. Children with ASD were found to have poorer quality attachment relationships, higher rates of inhibited attachment behaviours, and higher rates of behaviour and emotional problems. Associations were observed between attachment factors and behaviour and emotional problems in both the ASD and other developmental disability groups, with this relationship holding after controlling for ASD. Such research has important implications for our understanding of the cross-sectional relationships involved in ASD and associated behavioural disturbance, and highlights potential approaches to intervention.

The high rates of behaviour and emotional problems found within the ASD sample are consistent with extensive literature investigating rates of behaviour and emotional problems in the wider ASD population. Children with ASD are demonstrated to have higher rates of behaviour and emotional problems than typically developing children and children with other developmental disabilities (Brereton et al., 2006; Emerson, 2003; Tonge \& Einfeld, 2000). Parents of children with ASD in the current study reported high rates of on all DBC2 subscales, particularly the Disruptive and Anxiety subscales, consistent with Brereton et al. (2006) and Totsika et al. (2011). Importantly, the higher rates of Social Relating behaviour and emotional problems within children with ASD is expected, given this scale includes symptoms of autism. Finally, the current study found that children in both the ASD and other developmental disability groups had higher rates of behaviour and emotional problems than in a representative Australian ID sample (Einfeld \& Tonge, 1996a, 1996b); however these results are not unexpected, given that the current study recruited families who presented for a parent-training program targeting child behaviour and emotional problems (Sofronoff et al., 2018).

For attachment measures, children in the combined ID sample reported significantly more attachment difficulties than demonstrated in typically developing samples. Between groups, children with ASD were demonstrated to have less closeness in attachment relationships and more inhibited attachment behaviours than children with other developmental disabilities. This finding suggests that ASD symptomatology affects children's development of secure attachments beyond the impact of intellectual disability, consistent with previous research (Rutgers et al., 2004; Teague et al., 2017). The social 
communication and reciprocity difficulties characteristic of ASD may pose a barrier in the formation of secure attachments, potentially due to difficulties for children and caregivers alike in inferring each other's intent behind behaviours. Importantly, previous research has demonstrated that children with ASD without intellectual disability have comparable rates of secure attachment to the typically developing population (Bauminger et al., 2010; Chandler \& Dissanayake, 2013), suggesting that the combination of ASD and intellectual disability may impose additional challenges to the formation of secure attachments.

Finally, attachment factors were associated with child behaviour and emotional problems in both the ASD and other developmental disability groups, and were found to contribute uniquely beyond an ASD diagnosis. These associations between attachment and children's behaviour and emotional problems reflect substantive evidence from the typically developing literature (Fearon et al., 2010). Other studies with ASD samples have demonstrated associations between secure attachment and joint attention, play behaviours, and educational outcomes (Dolev, Oppenheim, Koren-Karie, \& Yirmiya, 2014; Marcu, Oppenheim, Koren-Karie, Dolev, \& Yirmiya, 2009; Naber et al., 2008, 2007), demonstrating that secure attachment is associated with positive developmental outcomes. Future work should consider examining whether the association between attachment and children's socioemotional development longitudinally as found in typically developing children (Fearon et al., 2010; van Ijzendoorn et al., 1999), with very little such research available (Teague et al., 2017). Future work may also consider examining the nuance of the relationship between attachment and child behaviour and emotional problems in children with ASD with comorbid ID, including the potential role of caregiving environment factors such as parents' mental health, attachment quality, and parenting practices (Bauminger et al., 2010; Teague et al., 2018).

This research has important implications for interventions targeting child behaviour and emotional problems in ASD samples. Such interventions may benefit from the addition of an attachment framework which addresses the child's difficulties in using caregivers as a co-regulatory agent of emotions (Fearon et al., 2010; Greenberg et al., 1993; Sivaratnam et al., 2015). Strategies designed to improve parents' ability to understand both their own and their child's behaviours, thoughts, and feelings, and foster positive relationships with children, may be particularly beneficial. Such strategies may already be in place in positive parenting programs (e.g. Sanders, Mazzucchelli, \& Studman, 2004), and work is needed to investigate the impact of these programs in terms of the attachment-relationship. Attachment- 
based interventions targeting other aspects of socioemotional development in children with ASD have demonstrated success (e.g. joint attention in Poslawsky et al., 2015), holding promise for the development of attachment-based interventions for behaviour and emotional problems.

This study has a number of limitations to be addressed in future work. Firstly, families were recruited from a parenting program addressing behaviour and emotional problems in children with heterogeneous causes of ID, resulting in high rates of child behaviour and emotional problems in the current sample. This may limit the generalisability of our findings on attachment factors and child behaviour and emotional problems in children with ASD, as this relationship may not be reflected in children with lower levels of behaviour and emotional problems. Further, the comparison group consisted of a representative sample of children with ID from the community, resulting in a heterogeneity in cause of ID. Secondly, the study used relatively small groups which may have impacted on the statistical power of results. However, even with small sample sizes, differences were found between groups for both attachment quality and child behaviour and emotional problems.

Finally, all measures in this study were reliant on caregiver-reporting, including the use of proxy measures of attachment quality. Measurement of attachment in children with ASD is notably difficult, with overlaps in symptomatology and difficulty in implementing measures without modification (see McKenzie and Dallas, 2017 for a review). While observational measures of attachment quality such as the Strange Situation paradigm are considered "gold-standard" attachment measures, the Disturbances of Attachment Interview (DAI) and the Child-Parent Relationship Scale (CPRS) have both been used previously within ASD and intellectual disability samples (e.g. Giltaij, Sterkenburg, \& Schuengel, 2015; Totsika, Hastings, Vagenas, \& Emerson, 2014). Future work could investigate the suitability of different attachment measures for children with ASD, considering the qualitative differences in attachment behaviours between children with ASD and typically developing children.

This study has important implications for the assessment and management of children with ASD. First, children with ASD are in need of interventions targeting their elevated levels of behaviour and emotional problems. The scale and scope of this problem may warrant a large, public health approach, given the consistently high levels of behaviour and emotional problems reported in the literature across ASD samples (Gray, Keating, et al., 
2012; Mazzucchelli \& Sanders, 2011). Second, children with ASD may also benefit from interventions targeting attachment quality. In particular, interventions aiming to help children with ASD to use their caregiver as a "safe-haven" when experiencing distress and to help caregivers to act as a co-regulatory agent of their child's emotions, may assist children with ASD to reduce their behaviour and emotional problems and follow a positive developmental pathway (e.g. Newman et al. 2014). Finally, children with developmental disabilities other than ASD also appear to be in need of interventions to help address both their behaviour and emotional problems and their attachment quality. Thus, secure attachment appears to act in a protective role for both groups and may be an important target for reducing child behaviour and emotional problems across the child disability population.

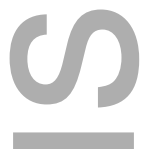

\section{References}

Ainsworth, M. D. S. (1985). Attachments across the life span. Bulletin of the New York Academy of Medicine, 61(9), 792-812.

Ainsworth, M. D. S., Bell, S. M., \& Stayton, D. (1971). Individual differences in strange situation behavior of one-year-olds. In H. R. Schaffer (Ed.), The Origins of Human Social Relations (pp. 17-57). London, UK: Academic Press.

Ainsworth, M. D. S., Bell, S. M., \& Stayton, D. J. (1974). Infant-mother attachment and social development: socialisation as a product of reciprocal responsiveness to signals. In M. P. Richards (Ed.), The Introduction of the Child into a Social World (pp. 95-135). London: Cambridge University Press.

Ainsworth, M. D. S., Blehar, M. C., Waters, E., \& Wall, S. (1978). Patterns of Attachment: A Psychological Study of the Strange Situation. Oxford, England: Lawrence Erlbaum Associates.

American Psychiatric Association. (1980). Diagnostic and statistical manual of mental disorders (3rd ed.). Washington, DC: American Psychiatric Association.

Australian Bureau of Statistics. (2013). 2033.0.55.001 - Census of population and housing: socio-economic indexes for areas (SEIFA), Australia, 2011. ICPSR Data Holdings.

Bauminger, N., Solomon, M., \& Rogers, S. J. (2010). Externalizing and internalizing behaviors in ASD. Autism Research, 3(3), 101-112. 
Attachment and behaviour and emotional problems in ASD

Bender, R., \& Lange, S. (2001). Adjusting for multiple testing - when and how? Journal of Clinical Epidemiology, 54(4), 343-349.

Bettelheim, B. (1959). Feral children and autistic children. American Journal of Sociology, 64(5), 455-467.

Bowlby, J. (1969). Attachment and Loss, Volume 1: Attachment. New York: Basic Books.

Bowlby, J. (1973). Attachment and Loss, Volume 2: Separation: anxiety and anger. New York: Basic Books.

Bowlby, J. (1977). The making and breaking of affectional bonds. I. Aetiology and psychopathology in the light of attachment theory. The British Journal of Psychiatry, $130(3), 201-210$.

Brereton, A. V, Tonge, B. J., \& Einfeld, S. (2006). Psychopathology in children and adolescents with autism compared to young people with intellectual disability. Journal of Autism and Developmental Disorders, 36(7), 863-870.

Bruininks, R., Hill, B., \& Morreau, L. (1988). Prevalence and implications of maladaptive behaviors and dual diagnosis in residential and other service programs. New York, NY: Springer-Verlag.

Bruni, T. P. (2014). Test review: social responsiveness scale - second edition (SRS-2). Journal of Psychoeducational Assessment, 32(4), 365-369.

Chandler, F., \& Dissanayake, C. (2013). An investigation of the security of caregiver attachment during middle childhood in children with high-functioning autistic disorder. Autism, 18(5), 485-492.

Cohen, J. (1988). Statistical power analysis for the behavioral sciences. In Statistical Power Analysis for the Behavioral Sciences (2nd ed.). Hillsdale, NJ: Erlbaum.

Constantino, J. N., \& Gruber, C. (2012). Social Responsiveness Scale (SRS-2). https://doi.org/10.1007/978-1-4419-1698-3_296

Cortina, M., \& Liotti, G. (2010). Attachment is about safety and protection, intersubjectivity is about sharing and social understanding: the relationships between attachment and intersubjectivity. Psychoanalytic Psychology, 27(4), 410-441.

Davidson, C., O’Hare, A., Mactaggart, F., Green, J., Young, D., Gillberg, C., \& Minnis, H. 
Attachment and behaviour and emotional problems in ASD

(2015). Social relationship difficulties in autism and reactive attachment disorder: Improving diagnostic validity through structured assessment. Research in Developmental Disabilities, 40, 63-72.

Dolev, S., Oppenheim, D., Koren-Karie, N., \& Yirmiya, N. (2014). Early attachment and maternal insightfulness predict educational placement of children with autism. Research in Autism Spectrum Disorders, 8(8), 958-967.

Driscoll, K., \& Pianta, R. (2011). Mothers' and fathers' perceptions of conflict and closeness in parent-child relationships during early childhood. Journal of Early Childhood \& Infant Psychology, 7, 1-24.

Einfeld, S., Piccinin, A. M., Mackinnon, A., Hofer, S. M., Taffe, J., Gray, K. M., ... Tonge, B. J. (2006). Psychopathology in young people with intellectual disability. JAMA, 296(16), 1981-1989.

Einfeld, S., \& Tonge, B. J. (1995). The Developmental Behavior Checklist: the development and validation of an instrument to assess behavioral and emotional disturbance in children and adolescents with mental retardation. Journal of Autism and Developmental Disorders, 25(2), 81-104. Retrieved from http://www.ncbi.nlm.nih.gov/pubmed/7559289

Einfeld, S., \& Tonge, B. J. (1996a). Population prevalence of psychopathology in children and adolescents with intellectual disability: I rationale and methods. Journal of Intellectual Disability Research, 40(2), 91-98.

Einfeld, S., \& Tonge, B. J. (1996b). Population prevalence of psychopathology in children and adolescents with intellectual disability: II epidemiological findings. Journal of Intellectual Disability Research, 40(2), 99-109.

Einfeld, S., \& Tonge, B. J. (2002). Developmental Behaviour Checklist (DBC) (2nd ed.). Melbourne, Australia: Monash University Centre for Developmental Psychiatry and Psychology.

Emerson, E. (2003). Prevalence of psychiatric disorders in children and adolescents with and without intellectual disability. Journal of Intellectual Disability Research, 47(Pt 1), 5158.

Emerson, E., Einfeld, S., \& Stancliffe, R. J. (2010). The mental health of young children with 
intellectual disabilities or borderline intellectual functioning. Social Psychiatry and Psychiatric Epidemiology, 45(5), 579-587.

Emerson, E., \& Hatton, C. (2007). Mental health of children and adolescents with intellectual disabilities in Britain. The British Journal of Psychiatry, 191(6), 493-499.

Fearon, R. P., Bakermans-Kranenburg, M. J., Van IJzendoorn, M. H., Lapsley, A. M., \& Roisman, G. I. (2010). The significance of insecure attachment and disorganization in the development of children's externalizing behavior: a meta-analytic study. Child Development, 81(2), 435-456.

Folstein, S., \& Rutter, M. (1977a). Genetic influences and infantile autism. Nature, Vol. 265, pp. $726-728$.

Folstein, S., \& Rutter, M. Infantile autism: a genetic study of 21 twin pairs. , 18 Journal of Child Psychology and Psychiatry and Allied Disciplines 297-321 (1977).

Frazier, T. W., Ratliff, K. R., Gruber, C., Zhang, Y., Law, P. a, \& Constantino, J. N. (2014). Confirmatory factor analytic structure and measurement invariance of quantitative autistic traits measured by the Social Responsiveness Scale-2. Autism, 18(1), 31-44.

Giltaij, H. P., Sterkenburg, P. S., \& Schuengel, C. (2015). Psychiatric diagnostic screening of social maladaptive behaviour in children with mild intellectual disability: differentiating disordered attachment and pervasive developmental disorder behaviour. Journal of Intellectual Disability Research, 59(2), 138-149.

Gleason, M. M., Fox, N. A., Drury, S., Smyke, A., Egger, H. L., Nelson, C. A., ... Zeanah, C. H. (2011). Validity of evidence-derived criteria for reactive attachment disorder: indiscriminately social/disinhibited and emotionally withdrawn/inhibited types. Journal of the American Academy of Child and Adolescent Psychiatry, 50(3), 216-231.

Gray, K. M., Keating, C. M., Taffe, J., Brereton, A., Einfeld, S., \& Tonge, B. J. (2012). Trajectory of behavior and emotional problems in autism. American Journal on Intellectual and Developmental Disabilities, 117(2), 121-133.

Gray, K. M., Piccinin, A. M., Hofer, S. M., Mackinnon, A., Bontempo, D. E., Einfeld, S., ... Tonge, B. J. (2011). The longitudinal relationship between behavior and emotional disturbance in young people with intellectual disability and maternal mental health. Research in Developmental Disabilities, 32(3), 1194-1204. 
Gray, K. M., Sweeney, D. J., Keating, C. M., Taffe, J. R., Einfeld, S., Reardon, T. C., \& Tonge, B. J. (2012). Examining behaviour and emotional problems in preschool children with developmental delay. Poster Presented at the International Meeting for Autism Research. Toronto, ON.

Gray, K. M., Tonge, B. J., Einfeld, S., Gruber, C., \& Klein, A. (2018). Developmental behavior checklist 2 (DBC2). Torrance, CA: WPS Publishing.

Gray, K. M., Tonge, J., Taffe, J., Sanders, M. R., Sofronoff, K., \& Einfeld, S. (2016). Behaviour and emotional problems in children with developmental disabilities: results from an Australian public health intervention. Journal of Intellectual Disability Research, 60(7), 674.

Green, J. (2003). Are attachment disorders best seen as social impairment syndromes? Attachment \& Human Development, 5(3), 259-264.

Greenberg, M. T., Speltz, M. L., \& Deklyen, M. (1993). The role of attachment in the early development of disruptive behavior problems. Development and Psychopathology, 5(12), 191-213.

Herring, S., Gray, K. M., Taffe, J., Tonge, B., Sweeney, D., \& Einfeld, S. (2006). Behaviour and emotional problems in toddlers with pervasive developmental disorders and developmental delay: associations with parental mental health and family functioning. Journal of Intellectual Disability Research, 50(Pt 12), 874-882.

Holland, A. S., \& McElwain, N. L. (2013). Maternal and paternal perceptions of coparenting as a link between marital quality and the parent-toddler relationship. Journal of Family Psychology, 27(1), 117-126.

Huebner, R., \& Thomas, K. (1995). The relationship between attachment, psychopathology, and childhood disability. Rehabilitation Psychology, 40(2), 111-124.

Janssen, C. G. C., Schuengel, C., \& Stolk, J. (2002). Understanding challenging behaviour in people with severe and profound intellectual disability: a stress-attachment model. Journal of Intellectual Disability Research, 46(6), 445-453.

Kanner, L. (1943). Autistic disturbances of affective contact. Nervous Child, 2, 217-250.

Koren-Karie, N., Oppenheim, D., Dolev, S., \& Yirmiya, N. (2009). Mothers of securely attached children with autism spectrum disorder are more sensitive than mothers of 
Attachment and behaviour and emotional problems in ASD

insecurely attached children. Journal of Child Psychology and Psychiatry, and Allied Disciplines, 50(5), 643-650.

Lambert, N. M., \& Windmiller, M. (1981). AAMD Adaptive Behavior Scale (School). Montley, CA: McGraw Hill.

Marcu, I., Oppenheim, D., Koren-Karie, N., Dolev, S., \& Yirmiya, N. (2009). Attachment and symbolic play in preschoolers with autism spectrum disorders. Journal of Autism and Developmental Disorders, 39, 1321-1328.

Mayes, S. D., Calhoun, S. L., Waschbusch, D. A., \& Baweja, R. (2017). Autism and reactive attachment/disinhibited social engagement disorders: co-occurrence and differentiation. Clinical Child Psychology and Psychiatry, 22(4), 620-631.

Mazzucchelli, T. G., \& Sanders, M. R. (2011). Preventing behavioural and emotional problems in children who have a developmental disability: a public health approach. Research in Developmental Disabilities, 32(6), 2148-2156.

McCarthy, J., Hemmings, C., Kravariti, E., Dworzynski, K., Holt, G., Bouras, N., \& Tsakanikos, E. (2010). Challenging behavior and co-morbid psychopathology in adults with intellectual disability and autism spectrum disorders. Research in Developmental Disabilities, 31(2), 362-366.

McKenzie, R., \& Dallos, R. (2017). Autism and attachment difficulties: Overlap of symptoms, implications and innovative solutions. Clinical Child Psychology and Psychiatry, 135910451770732. https://doi.org/10.1177/1359104517707323

Naber, F. B. A., Bakermans-Kranenburg, M. J., van Ijzendoorn, M. H., Swinkels, S. H. N., Buitelaar, J. K., Dietz, C., ... van Engeland, H. (2008). Play behavior and attachment in toddlers with autism. Journal of Autism and Developmental Disorders, 38(5), 857-866.

Naber, F. B. A., Swinkels, S. H. N., Buitelaar, J. K., Dietz, C., Van Daalen, E., BakermansKranenburg, M. J., ... Van Engeland, H. (2007). Joint attention and attachment in toddlers with autism. Journal of Abnormal Child Psychology, 35(6), 899-911.

Newman, L., Perry, N., Brown, A., Murray, E., Byrne, J., \& Dunlop, A. (2014). Parenting with feeling: group parenting intervention for substance dependent parents and their infants. Drug and Alcohol Review, 33, 48.

O’Connor, E. E., Scott, M. A., McCormick, M. P., \& Weinberg, S. L. (2014). Early mother- 
Attachment and behaviour and emotional problems in ASD

child attachment and behavior problems in middle childhood: the role of the subsequent caregiving environment. Attachment and Human Development, 16(6), 590-612.

Pianta, R. (2015). Child-Parent Relationship (Short Form). In J. Johnson, K. Smith, \& H. Joshi (Eds.), Millennium Cohort Study Psychological, Developmental and Health Inventories (pp. 54-56). London: Centre for Longitudinal Studies.

Poslawsky, I. E., Naber, F. B., Bakermans-Kranenburg, M. J., van Daalen, E., van Engeland, H., \& van IJzendoorn, M. H. (2015). Video-feedback intervention to promote positive parenting adapted to autism (VIPP-AUTI): a randomized controlled trial. Autism, 19(5), $588-603$.

Rice, L. J., Emerson, E., Gray, K. M., Howlin, P., Tonge, B. J., Warner, G. L., \& Einfeld, S. (2018). Concurrence of the strengths and difficulties questionnaire and developmental behaviour checklist among children with an intellectual disability. Journal of Intellectual Disability Research, 62(2), 150-155.

Russell, G., Mandy, W., Elliott, D., White, R., Pittwood, T., \& Ford, T. (2019). Selection bias on intellectual ability in autism research : a cross-sectional review and meta-analysis. Molecular Autism, 10(9), 1-10.

Rutgers, A. H., Bakermans-Kranenburg, M. J., van Ijzendoorn, M. H., \& van BerckelaerOnnes, I. A. (2004). Autism and attachment: a meta-analytic review. Journal of Child Psychology and Psychiatry, 45(6), 1123-1134.

Sanders, M. R., Mazzucchelli, T. G., \& Studman, L. J. (2004). Stepping Stones Triple P: the theoretical basis and development of an evidence-based positive parenting program for families with a child who has a disability. Journal of Intellectual and Developmental Disability, 29(3), 265-283.

Silber, S. (1989). Family Influences on Early Development. Topics in Early Childhood Special Education, 8(4), 1-23.

Sivaratnam, C. S., Newman, L., Tonge, B. J., \& Rinehart, N. J. (2015). Attachment and emotion processing in children with autism spectrum disorders: neurobiological, neuroendocrine, and neurocognitive considerations. Review Journal of Autism and Developmental Disorders, 2(2), 222-242.

Smyke, A. T., Dumitrescu, A., \& Zeanah, C. H. (2002). Attachment disturbances in young 
Attachment and behaviour and emotional problems in ASD

children. I: the continuum of caretaking casualty. Journal of the American Academy of Child and Adolescent Psychiatry, 41(8), 972-982.

Sofronoff, K., Gray, K. M., Einfeld, S., \& Tonge, B. J. (2018). Supporting families of children with a disability. In M. Sanders \& T. Mazzuchelli (Eds.), The Power of Positive Parenting: Transforming the Lives of Children, Parents, and Communities Using the Triple P System (pp. 442-454). New York, NY: Oxford University Press (OUP).

Sparrow, S. S., Cicchetti, D. V, \& Balla, D. A. (2005). The Vineland Adaptive Behaviour Scales (VABS-II) (2nd ed.). NCS Pearson Inc.

SPSS. (2013). IBM SPSS Statistics for Windows Version 22.0. Armonk NY, USA: IBM Corp. Sroufe, L. A. (2005). Attachment and development: a prospective, longitudinal study from birth to adulthood. Attachment \& Human Development, 7(4), 349-367.

Stern, D. N. (2004). The Present Moment in Psychotherapy and Everyday Life (Norton Series on Interpersonal Neurobiology). New York: W. W. Norton.

Szatmari, P., Zwaigenbaum, L., Georgiades, S., Elsabbagh, M., Waddell, C., Bennett, T., ... Volden, J. (2016). Resilience and developmental health in autism spectrum disorder. In M. Hodes \& S. Gau. (Eds.), Positive Mental Health, Fighting Stigma and Promoting Resilieney for Children and Adolescents (pp. 91-109). New York: Academic Press/Elsevier.

Taffe, J. R., Gray, K. M., Einfeld, S., Dekker, M. C., Koot, H. M., Emerson, E., ... Tonge, B. J. (2007). Short form of the developmental behaviour checklist. American Journal on Mental Retardation, 112(1), 31-39.

Taffe, J. R., Tonge, B. J., Gray, K. M., \& Einfeld, S. (2008). Extracting more information from behaviour checklists by using components of mean based scores. International Journal of Methods in Psychiatric Research, 17(4), 232-240.

Teague, S. J., Gray, K. M., Tonge, B. J., \& Newman, L. K. (2017). Attachment in children with autism spectrum disorder: a systematic review. Research in Autism Spectrum Disorders, 35, 35-50.

Teague, S. J., Newman, L. K., Tonge, B. J., Gray, K. M., Aery, A., Andersson, E., ... Viney, R. (2018). Caregiver mental health, parenting practices, and perceptions of child attachment in children with autism spectrum disorder. Journal of Autism and 
Attachment and behaviour and emotional problems in ASD

Developmental Disorders, 48(8), 2642-2652.

Tonge, B., \& Einfeld, S. (2000). The trajectory of psychiatric disorders in young people with intellectual disabilities. Australian and New Zealand Journal of Psychiatry, 34(1), 80 84.

Totsika, V., Hastings, R. P., Emerson, E., Lancaster, G. A., \& Berridge, D. M. (2011). A population-based investigation of behavioural and emotional problems and maternal mental health: associations with autism spectrum disorder and intellectual disability. Journal of Child Psychology and Psychiatry and Allied Disciplines, 52(1), 91-99.

Totsika, V., Hastings, R. P., Vagenas, D., \& Emerson, E. (2014). Parenting and the behavior problems of young children with an intellectual disability: concurrent and longitudinal relationships in a population-based study. American Journal on Intellectual and Developmental Disabilities, 119(5), 422-435.

Vaillancourt, T., Haltigan, J. D., Smith, I., Zwaigenbaum, L., Szatmari, P., Fombonne, E., ... Bryson, S. (2017). Joint trajectories of internalizing and externalizing problems in preschool children with autism spectrum disorder. Development and Psychopathology, 29(01), 203-214.

van Ijzendoorn, M. H., Goldberg, S., Kroonenberg, P. M., \& Frenkel, O. J. (1992). The relative effects of maternal and child problems on the quality of attachment: a metaanalysis of attachment in clinical samples. Child Development, 63(4), 840-858.

van Ijzendoorn, M. H., Rutgers, A. H., Bakermans-kranenburg, M. J., Swinkels, S. H. N., Daalen, E. Van, Dietz, C., ... Anna, H. (2007). Parental sensitivity and attachment in children with Autism Spectrum Disorder: comparison with children with mental retardation, with language delays, and with typical development. Child Development, 78(2), 597-608.

van Ijzendoorn, M. H., Rutgers, A. H., Bakermans-Kranenburg, M. J., Swinkels, S. H. N., van Daalen, E., Dietz, C., ... van Engeland, H. (2007). Parental sensitivity and attachment in children with autism spectrum disorder: comparison with children with mental retardation, with language delays, and with typical development. Child Development, 78(2), 597-608.

van Ijzendoorn, M. H., Schuengel, C., \& Bakermans-Kranenburg, M. J. (1999). Disorganized 
Attachment and behaviour and emotional problems in ASD

attachment in early childhood: meta-analysis of precursors, concomitants, and sequelae. Development and Psychopathology, 11(2), 225-249.

Waters, E., \& Deane, K. E. (1985). Defining and assessing individual differences in attachment relationships: Q-methodology and the organization of behavior in infancy and early childhood. Monographs of the Society for Research in Child Development, $50(1-2), 41-65$.

Werner, E. (1989). High-risk children in young adulthood: a longitudinal study from birth to 32 years. American Journal of Orthopsychiatry, 59(1), 72-81.

Willemsen-Swinkels, S. H., Bakermans-Kranenburg, M. J., Buitelaar, J. K., van IJzendoorn, M. H., \& van Engeland, H. (2000). Insecure and disorganised attachment in children with a pervasive developmental disorder: relationship with social interaction and heart rate. Journal of Child Psychology and Psychiatry and Allied Disciplines, 41(6), 759767.

Woodman, A. C., Smith, L. E., Greenberg, J. S., \& Mailick, M. R. (2015). Change in autism symptoms and maladaptive behaviors in adolescence and adulthood: the role of positive family processes. Journal of Autism and Developmental Disorders, 45(1), 111-126.

Zeanah, C. H., Smyke, A. T., Koga, S. F., \& Carlson, E. (2005). Attachment in institutionalized and community children in Romania. Child Development, 76(5), 10151028.

\section{Tables and Figures}

Table 1

Means, Standard Deviations and Comparisons between the ASD and Other Developmental Disabilities (DD) Groups for Parent-Child Dyad Participants' Demographics

\begin{tabular}{lcccc} 
& & & & \\
& ASD & Other DD & & \\
& $(\mathrm{n}=28)$ & $(\mathrm{n}=20)$ & Comparison & $\mathrm{p}$ \\
& $\mathrm{M}(\mathrm{SD})$ & $\mathrm{M}(\mathrm{SD})$ & & \\
\hline Gender & $79 \%$ male & $50 \%$ male & $X^{2}(2, \mathrm{~N}=48)=4.29$ & $.04^{*}$ \\
Age (years) & $5.3(2.1)$ & $5.0(1.5)$ & $\mathrm{t}(46)=0.36$ & .72
\end{tabular}


Attachment and behaviour and emotional problems in ASD

Socio-Economic Indexes for Areas (SEIFA)

$$
6.5(2.4) \quad 6.5(2.4) \quad \mathrm{t}(46)=-0.51 \quad .96
$$

Vineland Adaptive Behaviour Composite

$64.5(15.7)$

$65.3(9.7)$

$\mathrm{t}(46)=-0.20$ .84

SRS-Total Social Responsiveness

$80.6(9.2)$

$64.6(5.7)$

$\mathrm{t}(46)=6.8$

$.00 * *$

$* \mathrm{p}<.05$

$* * \mathrm{p}<.01$

Table 2

Means, Standard Deviations, and Comparisons between ASD and Other Developmental

Disabilities (DD) Groups for Attachment Relationship Quality (CPRS), Child Attachment

Disturbances (DAI), and Child Behaviour and Emotional Problems (DBC2)

\begin{tabular}{|c|c|c|c|c|c|c|}
\hline \multirow{2}{*}{ Behaviour and emotional problems } & \multicolumn{2}{|c|}{$\begin{array}{c}\text { ASD } \\
(\mathrm{n}=28) \\
\mathrm{M}(\mathrm{SD})\end{array}$} & \multicolumn{2}{|c|}{$\begin{array}{l}\text { Other DD } \\
(\mathrm{n}=20) \\
\mathrm{M}(\mathrm{SD})\end{array}$} & $\begin{array}{c}\mathrm{t} \text {-test } \\
(\mathrm{df}=46)\end{array}$ & $\mathrm{p}$ \\
\hline & & & & & & \\
\hline Total Behaviour Problem Score & 0.87 & $(0.29)$ & 0.47 & $(0.21)$ & 5.38 & $.00 * *$ \\
\hline Disruptive & 1.01 & $(0.37)$ & 0.65 & $(0.34)$ & 3.47 & $.00^{* *}$ \\
\hline Self-Absorbed & 0.84 & $(0.33)$ & 0.47 & $(0.22)$ & 4.34 & $.00 * *$ \\
\hline Communication Disturbance & 0.91 & $(0.46)$ & 0.44 & $(0.41)$ & 3.68 & $.00 * *$ \\
\hline Anxiety & 0.96 & $(0.42)$ & 0.43 & $(0.28)$ & 5.02 & $.00 * *$ \\
\hline Social Relating & 0.79 & $(0.32)$ & 0.31 & $(0.23)$ & 5.76 & $.00^{* *}$ \\
\hline \multicolumn{7}{|l|}{ Attachment Relationship } \\
\hline Total Positive Relationship (TPRS) & 48.64 & $(9.01)$ & 59.25 & $(8.25)$ & -4.16 & $.00 * *$ \\
\hline Conflict & 23.36 & $(6.63)$ & 21.85 & $(7.22)$ & 0.75 & .46 \\
\hline Closeness & 25.68 & $(5.09)$ & 29.15 & $(4.43)$ & -2.46 & $.02 *$ \\
\hline \multicolumn{7}{|l|}{ Attachment Disturbances } \\
\hline Inhibited & 4.71 & $(1.92)$ & 2.65 & $(2.11)$ & 3.52 & $.00 * *$ \\
\hline Disinhibited & 3.89 & $(2.04)$ & 4.40 & (1.96) & -0.86 & .39 \\
\hline Self-endangering & 1.07 & $(0.81)$ & 1.15 & $(0.88)$ & -0.32 & .75 \\
\hline Excessive clinging & 0.96 & $(0.64)$ & 0.70 & $(0.57)$ & 1.48 & .15 \\
\hline Fearful & 0.64 & $(0.62)$ & 0.70 & $(0.66)$ & -0.31 & .76 \\
\hline Controlling & 0.61 & $(0.57)$ & 0.70 & $(0.66)$ & -0.52 & .60 \\
\hline
\end{tabular}

This article is protected by copyright. All rights reserved 
Attachment and behaviour and emotional problems in ASD

$* * \mathrm{p}<.01$

$\wedge^{\wedge}$ mean item scores

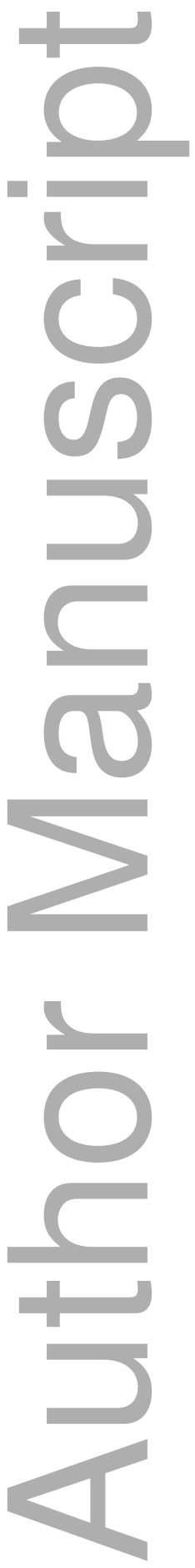

This article is protected by copyright. All rights reserved 
Attachment and behaviour and emotional problems in ASD

Table 3

Pearson's Correlations between Child Behaviour and Emotional Problems (DBC2 Mean Item Scores) and Child Attachment and ASD Symptoms for ASD and Other Developmental Disabilities (DD) Groups

\begin{tabular}{|c|c|c|c|c|c|c|c|c|}
\hline Behaviour and Emotional Problems & Age & Gender & SEIFA & $\begin{array}{l}\text { Vineland } \\
\text { ABC }\end{array}$ & $\begin{array}{l}\text { CPRS - Total } \\
\text { Positive } \\
\text { Attachment }\end{array}$ & $\begin{array}{c}\text { DAI } \\
\text { Inhibited }\end{array}$ & $\begin{array}{c}\text { DAI } \\
\text { Disinhibited }\end{array}$ & $\begin{array}{l}\text { SRS-2 } \\
\text { Total }\end{array}$ \\
\hline \multicolumn{9}{|l|}{ ASD Group } \\
\hline Total Behaviour Problem Score & .12 & -.12 & $-.50 * *$ & -.15 & $-.61 * *$ & .03 & .12 & $.50 * *$ \\
\hline Disruptive & -.02 & -.16 & -.32 & -.14 & $-.64 * *$ & -.02 & .03 & .19 \\
\hline Self-Absorbed & .03 & -.10 & $-.38 *$ & -.05 & -.36 & .09 & .30 & $.41 *$ \\
\hline Communication Disturbance & .30 & -.16 & -.35 & .05 & $-.43 *$ & -.05 & .02 & $.57 * *$ \\
\hline Anxiety & .25 & -.04 & $-.50 * *$ & -.29 & $-.50 * *$ & .01 & -.11 & $.59 * *$ \\
\hline Social Relating & .02 & -.11 & -.36 & -.33 & $-.53 * *$ & $.43^{*}$ & .26 & $.60 * *$ \\
\hline \multicolumn{9}{|l|}{ Other DD Group } \\
\hline Total Behaviour Problem Score & -.20 & .26 & -.16 & -.02 & $-.48 *$ & .24 & .16 & $.48^{*}$ \\
\hline Disruptive & .22 & -.05 & -.12 & -.10 & $-.56 *$ & .24 & .24 & .33 \\
\hline Self-Absorbed & -.39 & .39 & .03 & -.22 & -.05 & .19 & .33 & .33 \\
\hline Communication Disturbance & $-.46^{*}$ & .29 & -.21 & .23 & -.14 & .09 & -.11 & .31 \\
\hline Anxiety & -.23 & .18 & -.24 & .17 & -.36 & .12 & -.20 & .29 \\
\hline Social Relating & -.20 & .11 & -.34 & .05 & -.42 & .00 & -.21 & $.50 *$ \\
\hline
\end{tabular}

$* * \mathrm{p}<.01$

This article is protected by copyright. All rights reserved 
Table 4

Multiple Regression Analyses for Child Behaviour and Emotional Problems (DBC2 Mean Item Scores) using Attachment and ASD Symptoms for the Combined Sample

\begin{tabular}{|c|c|c|c|c|c|c|c|c|c|c|c|c|}
\hline \multirow{2}{*}{ 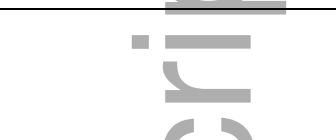 } & \multicolumn{4}{|c|}{ Total Behaviour Problem } & \multicolumn{4}{|c|}{ Disruptive } & \multicolumn{4}{|c|}{ Self-Absorbed } \\
\hline & $\operatorname{Adj} R^{2}$ & $\mathrm{~F}$ & $\beta$ & $\mathrm{p}$ & Adj $R^{2}$ & $\mathrm{~F}$ & $\beta$ & $\mathrm{p}$ & $\operatorname{Adj} R^{2}$ & $\mathrm{~F}$ & $\beta$ & $\mathrm{p}$ \\
\hline Model 1 & 0.57 & 24.01 & - & $.00^{\dagger}$ & 0.51 & 19.58 & - & $.00^{\dagger}$ & 0.25 & 6.92 & - & $.00 * *$ \\
\hline ASD Diagnosis & - & - & -0.21 & $.04 *$ & - & - & 0.01 & 0.94 & - & - & -0.23 & 0.09 \\
\hline SEIFA & - & - & -0.26 & $.01 * *$ & - & - & -0.19 & 0.05 & - & - & -0.16 & 0.2 \\
\hline DAI Disinhibited & - & - & 0.18 & 0.19 & - & - & 0.15 & 0.31 & - & - & 0.3 & $.03 *$ \\
\hline ASD Diagnosis & - & - & -0.43 & $.00 * *$ & - & - & -0.25 & 0.11 & - & - & -0.4 & $.01^{* *}$ \\
\hline SEIFA & - & - & -0.3 & $.02 *$ & - & - & -0.23 & 0.09 & - & - & -0.21 & 0.1 \\
\hline
\end{tabular}

\begin{tabular}{|c|c|c|c|c|c|c|c|c|c|c|c|c|}
\hline & $\operatorname{Adj} R^{2}$ & $\mathrm{~F}$ & $\beta$ & $\mathrm{p}$ & $\operatorname{Adj} R^{2}$ & $\mathrm{~F}$ & $\beta$ & $\mathrm{p}$ & $\operatorname{Adj} R^{2}$ & $\mathrm{~F}$ & $\beta$ & $\mathrm{p}$ \\
\hline Model 1 & 0.3 & 8.72 & - & $.00^{\dagger}$ & 0.51 & 19.42 & - & $.00^{\dagger}$ & 0.54 & 22.12 & - & $.00^{\dagger}$ \\
\hline CPRS & - & - & -0.39 & $.00^{* *}$ & - & - & -0.5 & $.00^{\dagger}$ & - & - & -0.43 & $.00^{\dagger}$ \\
\hline ASD Diagnosis & - & - & -0.22 & 0.09 & - & - & -0.26 & $.02 *$ & - & - & -0.4 & $.00^{\dagger}$ \\
\hline SEIFA & - & - & -0.24 & $.04 *$ & - & - & -0.31 & $.00^{* *}$ & - & - & -0.27 & $.01^{* *}$ \\
\hline Model 2 & 0.16 & 3.44 & - & $.02 *$ & 0.28 & 6.19 & - & $.00^{\dagger}$ & 0.44 & 11.37 & - & $.00^{\dagger}$ \\
\hline
\end{tabular}

This article is protected by copyright. All rights reserved 
Attachment and behaviour and emotional problems in ASD

\begin{tabular}{|c|c|c|c|c|c|c|c|c|c|c|c|c|}
\hline DAI Inhibited & - & - & 0.03 & 0.83 & - & - & 0.11 & 0.45 & - & - & 0.22 & 0.09 \\
\hline DAI Disinhibited & - & - & 0.07 & 0.64 & - & - & -0.03 & 0.82 & - & - & 0.12 & 0.31 \\
\hline ASD Diagnosis & - & - & -0.37 & $.02 *$ & - & - & -0.41 & $.00 * *$ & - & - & -0.49 & $.00^{\dagger}$ \\
\hline SEIFA & - & - & -0.26 & $.05^{*}$ & - & - & -0.31 & $.01 *$ & - & - & -0.28 & $.01 *$ \\
\hline
\end{tabular}

NOTES: $* \mathrm{p}<.05 ; * * \mathrm{p}<.01 ;{ }^{\dagger} \mathrm{p}<.001 ;$ standardised beta coefficients reported

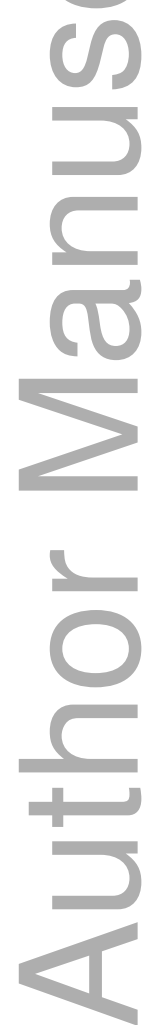

This article is protected by copyright. All rights reserved 


\section{University Library}

\section{- M M N E R VA A gateway to Melbourne's research publications}

Minerva Access is the Institutional Repository of The University of Melbourne

Author/s:

Teague, SJ;Newman, LK;Tonge, BJ;Gray, KM

Title:

Attachment and child behaviour and emotional problems in autism spectrum disorder with intellectual disability

Date:

2020-05-01

Citation:

Teague, S. J., Newman, L. K., Tonge, B. J. \& Gray, K. M. (2020). Attachment and child behaviour and emotional problems in autism spectrum disorder with intellectual disability. JOURNAL OF APPLIED RESEARCH IN INTELLECTUAL DISABILITIES, 33 (3), pp.475-487. https://doi.org/10.1111/jar.12689.

Persistent Link:

http://hdl.handle.net/11343/286937 